\title{
Vocabulary Learning Strategies Employed by Thai University Students across Four Academic Profiles
}

\author{
Sichabhat Boonnoon \\ Kasetsart University, Sakon Nakhon Province Campus, Thailand
}

\begin{abstract}
The present study explored the use of vocabulary learning strategies (VLS) by undergraduate Thai EFL students doing an academic reading course at a comprehensive university in northeastern Thailand and examined if there was a significant difference between the students' use of VLS and their academic majors. A five-point Likert-scale questionnaire with 41 items adapted from Jones's (2006) taxonomy of VLS which was categorized into 8 different strategies was administered to a group of 267 Thai undergraduate students purposively selected from across four academic majors-Business major (BM), Engineering major (EM), Agriculture major (AM), and Health science major (HM). The results revealed that the students were moderate users of VLS, with dictionary and note-taking strategies being reported as the most frequently used VLS and selective attention the least frequently used VLS. The results of One-way ANOVA showed that the students were significantly different $(p<.05)$ in using five out of eight strategies. Post hoc comparisons using Scheffe test showed that health science students used VLS more frequently than the rest of academic majors.
\end{abstract}

Index Terms - vocabulary learning strategies (VLS), Thai EFL students, academic major

\section{INTRODUCTION}

In Thailand, English has been learned and taught to the students at almost all levels as a foreign language. It is not as simple as is generally thought when it comes to learning English as a foreign language, though. To master the language, learners need to pay utmost attention to all details pertaining to the language knowledge including grammatical structure, vocabulary, and register. Of all the aforementioned aspects of the language knowledge, vocabulary seems to be the most important one, as once posited by Wilkins (1972) that "while without grammar very little can be conveyed, without vocabulary nothing can be conveyed" (pp. 111-112).

Vocabulary becomes even more pivotal when it comes to the fact that the students get involved with more advanced academic materials such as the ones for technical English courses and English for specific purposes. The students at Chalermphrakiat Sakon Nakhon Province Campus of Kasetsart University (CSCKU), having passed Foundation English III, opt to do Academic English Reading, among the available requirement courses, as their follow-up course. This course by nature requires the students to know extensive vocabulary in order to comprehend the academic texts relevant to their fields. When it comes to vocabulary in a text, especially in academic reading classes, technical vocabulary is vital for English language learning. Technical vocabulary is important for learners who have a specific purpose in language learning. It can be in the form of a normal word with a specific meaning that is different from its common meaning. Texts in specific context are therefore unavoidable for learners, and so they have to construct meaning by drawing on their previous knowledge.

However, research says that the learners still need help in the form of strategy instruction to deal with unfamiliar academic or technical vocabulary. With the help of vocabulary learning strategies, a large amount of vocabulary could be acquired (Coady \& Huckin, 1997) and the strategies are proved beneficial for students with different academic profiles. VLS can help learners take more control of their own learning, and so they can take more responsibility for their vocabulary learning (Scharle \& Szabo, 2000), as a result, they chose strategies suitable for the achievement of their goals and take account of their affective needs and work context (Suwanarak, 2015).

Numerous research works (Chinpakdee, Komol \& Sripatpan, 2011; Nomnian, \& Suraratdecha, 2014; Nirattisai, 2014; have been carried out in relation to the VLS used by Thai university EFL students and the results have shown that Thai university EFL leaners are moderate users of VLS. The directive suggestions derived from those research works are that Thai learners of English need to know and use appropriate and more learning strategies in order to enhance their vocabulary repositories. The strategies for learning vocabulary involve, for example, using a dictionary, keeping a vocabulary notebook, and asking for help with word meanings from peers or the teachers. However, to use vocabulary learning strategies more effectively, learners should be active and independent, and these states of being active and independent are, to be precise, the strategies per se, referred to as either cognitive or metacognitive strategies.

Still, not many researchers have investigated the repertoire of VLS used by Thai university students in the course of their academic or technical English studies, especially when the students are from across different academic majors. The author of the present investigation was, therefore, determined to explore what VLS were most or least frequently 
used by the students doing an academic reading course. The variation of VLS use by the students was also to be investigated.

It was expected that by drawing on the results of this study the English teachers as well as the academic community as a whole would further improve the students' English proficiency. With this study, the researcher wished to indirectly raise the students' level of awareness, make them recognize more effective vocabulary learning strategies for a given circumstance, and encourage them to discern their best VLS. Through this study, the instruction of English at the university level might thus be improved because the teachers would become more vigilant as to which VLS on the students' part need to be retooled and enhanced. The university management might also be prompted to evolve more effective language programmes which address the students' specific and individual needs. Moreover, the findings from this study would shed light on the strategies employed by the students from the four faculties in learning English vocabulary, and the roles those strategies play in enhancing their academic English vocabulary repertoires. To achieve these aims, the following two research questions were put:

1. What are the most frequently used vocabulary learning strategies among the students across four academic majors?

2. How do the types of vocabulary learning strategies vary across the academic majors?

\section{LITERATURE REVIEW}

\section{A. Vocabulary Learning Strategies (VLS)}

Nation (2001) avers that vocabulary learning strategies are an indispensible part of language learning strategies which are under the general learning strategy repository. Though it is difficult to exactly define the word strategy, the scholar puts forth the following aspects as what deserves the teacher's attention as a strategy. He states: "a strategy would to need to: (1) involve choice, that is, there are several strategies to choose from and one choice could be not to use the strategy; (2) be complex, that is, there are several steps to learn; (3) require knowledge and benefit from training; and (4) increase the efficiency and effectiveness of vocabulary learning and vocabulary use" (p. 326).

When it comes to the types of VLS and how they are classified, different researchers proposed their different classifications. Schmitt (2000) proposes two types of VLS: discovery and consolidation strategies. The first types are used for deriving the meaning of new words when the learners first come across them whereas the second types are used to consolidate meanings when the learners see the words again. Discovery strategies include determination and social strategies. On the contrary, consolidation strategies are further divided into four -social, memory, cognitive and metacognitive strategies. Schmitt classifies these VLS based partly on Oxford's (1990) taxonomy of language learning strategies which comprises social, memory, cognitive and metacognitive strategies.

This study draws on the VLS classification used by Jones (2006) who categorized the VLS into eight strategies: dictionary strategies, guessing strategies, study preference strategies, memory strategies, autonomy strategies, notetaking strategies, selective attention strategies, and social strategies.

Pertaining to dictionary strategies, several researchers (e.g. Fan, 2003; Rojananak \& Vitayapirak, 2015; Siddigh \& Shokrpur, 2012) reported that good students use dictionary strategies more frequently than poor students. On the type of dictionary, Baxter (1980) posits that in the long run learners stand to gain more from using a monolingual dictionary because they are forced to use more of L2 than L1. However, bilingual dictionaries were found to be preferred by EFL learners than monolingual dictionaries (Hsien-jen, 2001; Punduangkaew, 2018; Seddigh \& Shokrpur, 2012).

Guessing strategies refer to both guessing the meaning of the words from the context or from knowledge of word structure. In Schmitt's (1997) taxonomy, dictionary strategies and guessing strategies are categorized under determination strategies. According to $\mathrm{Gu}$ and Johnson (1996), guessing strategies are more frequently used by proficient learners than by non-proficient ones, and Hashemi \& Hadavi (2015) also confirmed the similar results. A meta-analyis of VLS used by EFL students conducted by Nematollahi et al. (2017) revealed that guessing strategies, particularly guessing from context are among the strategies most favoured by successful students.

Study preferences strategies are the ones that show the learners' preferences for studying vocabulary individually, with another person, or in group. Memory strategies are various techniques used by the learners to recall the vocabulary, or, as mentioned by Schmitt (1997), relating the new word to some previously learned knowledge. Examples of memory strategies include writing the new word several times, repeating the word aloud. Brahler and Walker (2007) refer to these strategies as mnemonics.

Autonomy strategies are closely related to the learners' motivation and taking responsibility for their own learning. For example, an autonomous learner does extensive reading outside of class or does a variety of out-of-class activities such as watching English movies and listening to English stories on Youtube.

Note taking strategies are a subcategory of cognitive strategies that emphasize mechanical aspects of learning (Seddigh \& Shokrpur, 2012). They help the learners to create a personal structure for the newly learned words (Schmitt, 1997). These strategies show the common types of words recorded by the learners such as common words, words that are of personal interest to them or words or phrases that learners think are useful. These strategies also include the language in which the learners record the words; that is, in English or in Thai. These strategies also entail the relevant information about the recorded words such as meaning, collocation, grammatical information, and register, etc.

Selective attention strategies are exactly under metacongintive strategies which involve planning, monitoring, evaluating and organizing one's own learning (Oxford, 1995). 
Finally, social strategies involve seeking a helping hand from other people in learning vocabulary. This include, for example, asking peers or teachers for the meaning. Interaction with native speakers is also an aspect of social strategies (Seddigh \& Shokrpur, 2012).

\section{B. Research in Relation to VLS and Academic Profiles}

Researchers' interest in academic majors in relation to the learners' employment of vocabulary learning strategies has been on the rise. Gu (2002), based on the assumption that specific tasks and contexts of learning may confound the relationship among gender, academic major, learning strategies and learning outcomes, conducted a large-scale survey among a group of adult Chinese EFL learners on their VLS. It was found that academic major was of less potent background factor. Science students and arts students differed significantly in the use VLS. Science students were keener on the analysis of word structure and word-formation rules than arts students who believed less in memorisation of words, and who believed that words can be picked up in context. Arts students also preferred to take more vocabulary notes than science students.

Siriwan's (2007) explored the types of vocabulary learning strategies used by 1481 Rajabhat University students across Thailand, the patterns of variations in frequency of VLS used according to gender, major field of study (English, science-oriented, and non-science-oriented), previous language learning experience, type of academic programme of study, and level of vocabulary proficiency, and investigated the relationships between frequency of student's reported strategy use and the five independent variables. The researcher found that on the whole, Rajabhat University students reported medium frequency of use of VLS, and major field of study was found to be among the seven factors that were strongly related to the use of VLS.

Puagsang and Intharaksa (2017) used a questionnaire and an individual semi-structured interview to survey 242 firstyear vocational students from three majors-engineering, accounting, and hotel and tourism from five vocational colleges in Krabi province, Thailand, to investigate their use of vocabulary learning strategies. The results in relation to academic majors were that VLS use significantly varied based on the participants' fields of study. The hotel and tourism students employed VLS significantly more frequently than accounting and engineering students in the memory strategies. On the whole, it was found that the hotel and tourism students reported a bit higher use of all VLS than engineering and accounting students though there were no significant differences in the rest of VLS.

Bernardo and Gonzales (2009) investigated the use of 53 common VLS by 202 Pilipino university students across five academic majors: liberal arts and education, computer science and engineering, business education, hospitality management, and allied medical science. Findings revealed statistically significant differences in the use of determination and social VLS across the disciplines. Another finding exhibited non-significant differences in the employment of memory, cognitive, and metacognitive VLS. The results also showed that the identified vocabulary learning strategies converged with each other. Scheffe-post-hoc procedure indicated significant differences between allied medical science students and liberal arts and education with liberal arts and education using determination VLS with greater frequency and between allied medical science and computer science and engineering with allied medical science employing social VLS with lesser frequency. So it is possible to conclude that different fields of study might incorporate different styles of learning vocabulary.

Han (2014) investigated the underlying factors of foreign language vocabulary learning strategies in order describe the students' use of vocabulary learning strategies and examine the differences in frequency of VLS use between the two language groups: alphabet-based languages (ABL) and character-based languages (CBL), and to identify the effects of gender, college major, motivation, and other variables on the use of VLS. The findings revealed that the students' major field of study was among the factors that were significantly related to student's overall VLS use.

As can be seen in the literature review, scant research has been replicated in order to confirm the significant relationship or difference in the use VLS and EFL students' academic profiles. There is still room for an investigation into the use of VLS among Thai EFL students across different academic majors, especially the students who are in the academic English setting where employment of various VLS repertoires is a must.

\section{Methodology}

\section{A. Research Design}

This study was based on the proposition that students employ diverse vocabulary learning strategies in understanding and acquiring a variety of vocabulary. Therefore, it draws on the theoretical support from Schmitt's (1997) taxonomy of vocabulary learning strategies which was further categorized in eight by Saddigh and Shokrpur (2014): dictionary, guessing, autonomy, note-taking, selective attention, social, study preferences, and memory strategies. A descriptive survey method was used in the present study to determine the vocabulary learning strategies employed by the students from each of the four identified disciplines and to elicit other pertinent information that might be required to answer further questions posed in this study.

\section{B. Participants}

Three hundred university students enrolled in Technical English, a course tailored to academic English reading, in a comprehensive university in the northeast of Thailand were purposively selected to take part in the study. However, 
only 267 questionnaires representing 89 per cent of the target number were considered appropriate for the data analysis because other questionnaires were faulty for incomplete answers. Of the total number of the participants, 105 were male, and 162 were female. The participants, who taking Technical English in the first term of the academic year 2018, ranged in age from 18-25 years, and were distributed across four academic profiles: Business major (BM, 96), Engineering major (EM, 80), Agriculture major (AM, 50), and Health science major (HM, 41). They had already passed the prerequisite Foundation English III course. They were, therefore, deemed to have possessed enough input to answer the questions pertaining to English vocabulary learning strategies.

\section{Data Collection Tool}

A close-ended questionnaire was employed as the data collection tool in this study. The questionnaire (in Thai, Conbrach's alpha $=0.87$ ) was slightly modified and adapted from the one constructed and used in a study by Seddigh and Shokrpur (2012). Since the present study was aimed at answering the similar research questions as put in the researchers' work, the questionnaire was deemed appropriate and thus adapted because it was at least designed to cover all the vocabulary learning strategies mentioned in the literature review.

The questionnaire was of two parts. The first part was a set of questions for deriving personal information from the participants, including age, gender, year of study, and faculty. The second part contained 41 close-ended items in Likert-type (always $=5$, often $=4$, sometimes $=3$, rarely $=2$, never $=1$ ) relevant to the approach to vocabulary learning the students reported employing. The 41 items were grouped into 8 categories-dictionary strategies, guessing strategies, study preferences, memory strategies, autonomy strategies, note-taking strategies, selective attention, and social strategies.

\section{Procedure}

The questionnaire, which was to be completed within a 20-minute time, was administered in 4 classes of Technical English. The students could ask any questions pertaining to the questionnaire during the administration. To make sure they answered the questionnaire honestly and enthusiastically, the researcher apprised them of the fact that all the data would be kept as highly confidential and would be used solely for educational purpose.

\section{E. Data Analysis}

Before analyzing the data, the 267 questionnaires responded by the students were thoroughly checked for completeness. The data was analyzed using SPSS 21.0. To find out the participants' vocabulary strategy use, descriptive statistics was applied. For each item in the questionnaire, the frequencies of responses were calculated in percentages. The means and standard deviations were calculated for the 41 strategies listed in the questionnaire. Chi-square tests were used to check whether the use of specific VLS varied significantly among the mean percentage scores of the 8 strategies in relation to the participants' gender, age, faculty, and year of study.

The following three levels of strategy use developed by Oxford (1990) were established based on the participants' self-reported frequency of VLS as the basis for the interpretation of the frequency levels of the use of VLS to see if the participants are high, medium or low strategy users.

TABLE I.

THE FREQUENCY LEVELS OF STRATEGY USE BY OXFORD (1990)

\begin{tabular}{|c|c|c|}
\hline High & Always & $4.5-5.0$ \\
& often & $3.5-4.4$ \\
\hline Medium & Sometimes & $2.5-3.4$ \\
\hline \multirow{2}{*}{ Low } & Seldom & $1.5-2.4$ \\
& Never & $1.0-1.4$ \\
\hline
\end{tabular}

\section{RESUlts AND DiscUSSION}

To determine the means and standard deviations of the eight categories of vocabulary learning strategies employed by the participants, descriptive statistics was computed. The results from the statistical analysis could answer the first research question.

\section{A. Answer to Research Question 1}

To answer research question 1 , the analyzed data has been summarized in Table 2 below for overall use of strategy and each strategy category. 
TABLE II.

OVERALl USE OF VOCABULARY LEARNING STRATEGIES (VLS) AMONG THE PARTICIPANTS (N=267)

\begin{tabular}{llll}
\hline Strategies & Mean & S.D. & Level of strategy use \\
\hline Dictionary & 3.57 & .68 & High \\
Guessing & 3.46 & 1.16 & Medium \\
Autonomy & 3.49 & .86 & Medium \\
Note-taking & 3.53 & .76 & High \\
Selective attention & 3.32 & .98 & Medium \\
Social & 3.40 & .94 & Medium \\
Study preferences & 3.44 & .81 & Medium \\
Memory & 3.34 & .76 & Medium \\
\hline Overall strategy use & 3.44 & 0.86 & Medium \\
\hline
\end{tabular}

Table 2 shows the overall strategy use among the students, with the mean of 3.44 , indicating that they were medium strategy users. As indicated in Table 2, in the eight categories, the most frequently used strategy was dictionary strategy (mean= 3.57, $\mathrm{SD}=.68$ ), followed by note-taking strategies (mean= 3.53, $\mathrm{SD}=.76$ ), autonomy strategies $(\mathrm{mean}=3.49$, $\mathrm{SD}=.86$ ), guessing strategies (mean=3.46, $\mathrm{SD}=1.16$ ), and study preferences strategies (mean=3.44, $\mathrm{SD}=.81$ ), respectively. The least frequently used strategy was selective attention strategy (mean=3.32, $\mathrm{SD}=.98$ ).

The descriptive statistics indicate that the VLSs most frequently used by Thai EFL undergraduate students at KUCSC were dictionary strategies. The findings are consistent with the findings of previous research done in the context of Thailand (Kongthong,2007; Pookchareon, 2011; Komol \& Sripetpun, 2014; Niratsai \& Chiramanee, 2014; Rojananak \& Vitayapitak, 2015) and in other countries such as Hashemin and Hadavi (2015) and recently Heidar and Hemayati (2017). One possible explanation is that the students are familiar with these well-known and widely-used strategies, especially when it comes to the fact that electronic dictionaries-online dictionaries in particular, have been incessantly popular among EFL learners across the world. Moreover, today's dictionaries are readily accessible through almost all types of mobile devices especially smartphones which make it a lot easier for English learners to access free online dictionaries at their disposal. From the author's direct observation, most of the students at this university have their own smartphones and they seem to use them as indispensible part of their lives. Panduangkaew (2018) asked a thoughtprovoking question pertaining to this fact, noting that using dictionaries would not have been as popular as it is now if it were still a heavy and thick book which is not portable for the students to carry to class or even for individual study.

With regards to the dictionary strategies employed by the participants, the frequency of 7 individual dictionary strategies is presented in Table 3.

TABLE III.

DICTIONARY STRATEGIES EMPLOYED BY THE PARTICIPANTS (N=267)

\begin{tabular}{|c|c|c|c|c|}
\hline & Dictionary strategies & Mean & Std. Deviation & Level of strategy use \\
\hline VLS1 & I use online dictionaries. & 4.07 & .96 & High \\
\hline VLS2 & I use English-Thai or Thai-English dictionaries. & 3.57 & 1.09 & High \\
\hline VLS3 & $\begin{array}{l}\text { I look up new words in a reading passage in the dictionary if } \\
\text { there are ones. }\end{array}$ & 3.66 & 1.11 & High \\
\hline VLS4 & $\begin{array}{l}\text { I look up a word in the dictionary if it is of personal interest to } \\
\text { me. }\end{array}$ & 3.73 & 1.21 & High \\
\hline VLS5 & I look at the different meanings of a word in the dictionary. & 3.35 & 1.09 & Medium \\
\hline VLS6 & $\begin{array}{l}\text { I look at examples of how a word is used when I look it up in } \\
\text { the dictionary. }\end{array}$ & 3.31 & 1.17 & Medium \\
\hline VLS7 & $\begin{array}{l}\text { When I look up a word in the dictionary, I look to see if it is a } \\
\text { noun, a verb, an adverb, etc. }\end{array}$ & 3.36 & 1.23 & medium \\
\hline
\end{tabular}

As shown in Table 4, the participants most frequently used online dictionaries (mean=4.07, SD=.96), looked up a word in the dictionary if it is of personal interest to them (mean=3.73, SD=1.21), and if there were new words in a reading passage, they looked them up in the dictionary (mean=3.66, $\mathrm{SD}=1.11$ ). They also reported using both EnglishThai and Thai-English dictionaries when they used (mean=3.57, $\mathrm{SD}=1.09$ ). The strategy of looking up a word in the dictionary if it is of personal interest was reported to be the second most frequently used dictionary strategy indicated that the participants used online dictionaries only when they wanted to know the meaning of the unknown word.

However, strategy 6, that is studying examples of how a word is used when consulting a dictionary, was reported to be the least frequently used strategy (mean=3.31, $\mathrm{SD}=1.17$ ) indicating that the students still used dictionaries in a quite conventional manner-for quick consultation (Bejoint \& Moulin, 1987, as cited in Fan, 2000). This fact shows that the students were not maximizing the use of dictionaries; that is, they did not spend a bit more time studying beyond the word definition, e.g. example sentences of the word. The lack of dictionary use skill could attribute to the participant's least frequent use of VLS6, as evidenced in Siddigh and Shokrpur's (2012). Given the fact that the participants were taking Academic English Reading at the time of the study, looking up academic words the students encountered in the course material might contribute to the higher frequency of VLS 4 and VLS 3 respectively. Previous research, with which this study was in accord, shows that EFL students looked up more academic English words than non-academic words (Thammajindarach \& Boonmoh, 2017). 
Note-taking strategies were the next most frequently used vocabulary learning strategies among the participants. With regards to the note-taking strategies employed by the participants, the frequency of 5 individual note-taking strategies is presented in Table 4.

TABLE IV.

NOTE-TAKING STRATEGIES EMPLOYED BY THE PARTICIPANTS (N=267)

\begin{tabular}{|l|l|c|c|c|}
\hline \multicolumn{1}{|c|}{ Note-taking strategies } & Mean & Std. Deviation & Level of strategy use \\
\hline VLS30 & I write down a word if I think is common. & 3.60 & 1.22 & High \\
\hline VLS31 & I write down a word that are of personal interest to me. & 3.65 & 1.08 & High \\
\hline VLS32 & I write down a word or phrases that I think are useful. & 3.48 & 1.08 & Medium \\
\hline VLS33 & I write down the definitions of English words in English. & 3.42 & 1.17 & Medium \\
\hline VLS34 & I write down information about words in Thai. & 3.49 & 1.19 & Medium \\
\hline VLS35 & $\begin{array}{l}\text { I write down information about words when I look them up in the } \\
\text { dictionary. }\end{array}$ & 3.59 & \multirow{2}{*}{ High } \\
\hline
\end{tabular}

Pertaining to the note-taking strategies, Table 4 shows that the most commonly used strategies, at the high frequency level, were writing down the words that are of personal interest (mean=3.65, SD=1.08), writing down a word if it is thought to be common (mean=3.60, $\mathrm{SD}=1.22$ ), and writing down information about words when looking them up in the dictionary (mean=3.59, $\mathrm{SD}=1.18$ ). Writing down information about words in Thai (VSL34) and writing down useful word or phrases (VLS32) achieved the very similar means (3.49 and 3.48 respectively). The least frequently used aspect of note-taking strategies is writing down the definitions of English words in English (mean=3.42, SD=1.17).

The findings in this study were inconsistent with those of Hashemi and Hadavi (2014), which indicated that notetaking strategies were reported as the least frequently used strategies among EFL medical students. The plausible explanation is that since the participants in this study enrolled in the academic English reading course, they took it seriously in taking notes of the English words they came across in the coursebook or the concerned information delivered by the teachers in class, and they did so to make sure that they passed the course. Regarding writing down a word that is of personal interest, the participants might have done this as a result of the academic English words abundantly used in the class material. Previous research (Mezek, 2013) indicated that taking notes is an important part of reading academic English material because EFL students who take more extensive notes while engaging with the text managed to learn more academic terms than the ones who did not do so. However, the fact that the participants depended heavily on their first language (Thai) when taking notes (see VLS34 and VLS33) was in accord with Saddigh and Shokrpur (2014) who found that most the students took notes in their own language, and only few used English to note or even write down the definitions of the words in English. The students in this study were Thai and they liked to use English-Thai dictionaries as well as take notes in Thai possibly because it was what they regularly did. The findings here suggest that Thai EFL learners should be forced to put English into use when taking notes of academic English words.

The participants reported using autonomy strategies (mean=3.49, $\mathrm{SD}=.86$ ) as the third frequently used category of strategies, followed by guessing strategies (mean=3.46, $\mathrm{SD}=1.16$ ). But these strategies did not appear as their most preferred strategies. The results came as quite a surprise because most previous research reported the high level of use of guessing strategies (Hadavi \& Hashemi, 2014; Mokhtar et al., 2018). It could be explained here that, to a certain extent, the participants did not try to learn new vocabulary items from context, though they indicated the use of autonomy strategies a bit more than guessing strategies, but that indication was simply reflecting their regular use of other common strategies-dictionary in particular. Guessing word meaning from context is regarded as a high-achiever's vocabulary learning strategy, but most of the participants in this study were moderate English achievers, hence their use of guessing strategies at a medium level. This prompts a systematic training of the students in extensive use of the guessing strategies to help them learn academic English words more effectively.

Selective attention strategies were found to achieve the lowest mean (mean=3.32, SD=.98) among the eight categories of VLS, indicating that the participants did not take these strategies seriously. Considering each item under this this category of VLS, it was found that VLS38 (I decide which words are important or unimportant for me to learn.), was reported being most frequently employed (mean=3.39, $\mathrm{SD}=1.13$ ), as indicated in Table 5 .

TABLE V.

SELECTIVE ATtention STRATEgIES EMPLOYED By THE PARTICIPANTS (N=300)

\begin{tabular}{|c|l|c|c|c|}
\hline \multicolumn{2}{|c|}{ Selective attention strategies } & Mean & Std. Deviation & Level of strategy use \\
\hline s36 & I have a schedule or routine that I follow for studying vocabulary. & 3.21 & 1.37 & Medium \\
\hline s37 & I think about my progress in vocabulary learning. & 3.36 & 1.17 & Medium \\
\hline s38 & I decide which words are important or unimportant for me to learn. & 3.39 & 1.13 & Medium \\
\hline
\end{tabular}

Referred to as metacognitive strategies in other research works, selective attention strategies help the learners in controlling their own cognition. These strategies pertain to overviewing and linking with the material previously known, paying attention, organizing, setting objectives and goals of study, self-monitoring, and self-assessing (Zare, 2012). According to Oxford (2003), to manage the holistic learning process, leaners employ these strategies. One interestingly salient note regarding the three selective attention strategies is that no high frequency level of use was found in this study. That selective attention strategies were found to be the least frequently used VLS among the participants was 
consistent with previous research (e.g. Rabadi, 2016; Al-Khasawneh, 2012), and this could be attributed to the participants' limited exposure to the target language outside of class, hence their not learning it consciously. Besides, since all the participants were not English majors, they might not have been taught or trained to rely on other useful vocabulary learning strategies other than the VLS they were most familiar with, such as dictionary strategies and notetaking ones.

\section{B. Answer to Research Question 2}

In order to determine any significant variation in strategy use pertaining to academic major, analyses of variance (ANOVA) were conducted using this factor as the independent variable and the eight categories of vocabulary learning strategies as dependent variables. The results are reported in Table 6.

TABLE VI.

SumMary OF THE USE OF VOCABUlary LEARning STRATEGIES ACROSS FOUR ACADEMIC MAJORS (N=267)

\begin{tabular}{|c|c|c|c|c|c|c|c|c|c|c|c|}
\hline \multirow[t]{2}{*}{ Strategies } & \multicolumn{2}{|c|}{$\mathrm{AB}$} & \multicolumn{2}{|c|}{ SE } & \multicolumn{2}{|c|}{$\mathrm{AI}$} & \multicolumn{2}{|c|}{$\mathrm{PH}$} & \multirow[t]{2}{*}{$\mathrm{F}$} & \multirow[t]{2}{*}{ Sig. } & \multirow[t]{2}{*}{ difference } \\
\hline & M & SD & M & SD & M & SD & M & SD & & & \\
\hline Dictionary & 3.52 & .68 & 3.59 & .63 & 3.68 & .75 & 3.56 & .66 & .605 & 612 & $\begin{array}{l}\mathrm{AM}>\mathrm{EM} ; \\
\mathrm{AM}>\mathrm{HM} \\
\mathrm{AM}>\mathrm{BM}\end{array}$ \\
\hline Guessing & 3.34 & 1.01 & 3.44 & 1.40 & 3.44 & 1.40 & 3.51 & 1.36 & .798 & .496 & $\begin{array}{c}\mathrm{HM}>\mathrm{EM}, \mathrm{AM} \\
\mathrm{HM}>\mathrm{BM}\end{array}$ \\
\hline Autonomy & 3.25 & .86 & 3.52 & .82 & 3.66 & .88 & 3.80 & .79 & $5.134^{*}$ & .002 & $\mathrm{HM}>\mathrm{AM}, \mathrm{HM}>\mathrm{EM}$ \\
\hline Note-taking & 3.47 & .75 & 3.50 & .79 & 3.63 & .74 & 3.64 & .75 & .817 & .486 & $\begin{array}{l}\mathrm{HM}>\mathrm{AM} \\
\mathrm{HM}>\mathrm{EM} \\
\mathrm{HM}>\mathrm{BM}\end{array}$ \\
\hline Selective attention & 3.05 & .99 & 3.37 & .93 & 3.45 & .98 & 3.65 & .93 & $4.425^{*}$ & .005 & $\begin{array}{l}\mathrm{HM}>\mathrm{AM} \\
\mathrm{HM}>\mathrm{EM} \\
\mathrm{HM}>\mathrm{BM}\end{array}$ \\
\hline Social & 3.19 & .85 & 3.48 & .99 & 3.51 & 1.14 & 3.60 & .64 & $2.650 *$ & .049 & $\begin{array}{l}\mathrm{HM}>\mathrm{AM} \\
\mathrm{HM}>\mathrm{EM} \\
\mathrm{HM}>\mathrm{BM}\end{array}$ \\
\hline Study preferences & 3.23 & .77 & 3.44 & .86 & 3.60 & .79 & 3.73 & .76 & $4.523 *$ & .004 & $\begin{array}{l}\mathrm{HM}>\mathrm{AM} \\
\mathrm{HM}>\mathrm{EM} \\
\mathrm{HM}>\mathrm{AM}\end{array}$ \\
\hline Memory & 3.16 & .72 & 3.30 & .79 & 3.57 & .799 & 3.56 & .65 & $4.664 *$ & .003 & $\begin{array}{l}\text { AM>HM; } \\
\mathrm{HM}>\mathrm{EM} ; \\
\mathrm{HM}>\mathrm{BM}\end{array}$ \\
\hline Total & 3.27 & 0.82 & 3.45 & 0.90 & 3.56 & 0.93 & 3.63 & 0.81 & $3.556 *$ & .015 & $\begin{array}{l}\mathrm{HM}>\mathrm{AM} \\
\mathrm{HM}>\mathrm{EM} ; \\
\mathrm{HM}>\mathrm{BM}\end{array}$ \\
\hline $\mathrm{n}$ & \multicolumn{2}{|c|}{96} & \multicolumn{2}{|c|}{80} & \multicolumn{2}{|c|}{50} & \multicolumn{2}{|c|}{41} & & & \\
\hline
\end{tabular}

As indicated in Table 6, findings revealed statistically significant differences $(p<.05)$ in the participants' use of the five categories of VLSs: autonomy, selective attention, social, and study preferences. However, the data exhibited nonsignificant differences for dictionary, guessing, and note-taking strategies, respectively. Post hoc comparisons using Scheffe test showed that health science students used VLSs more frequently $(\mathrm{M}=3.63)$ than the rest of the groups of students.

The findings here are in line with other several research works which reported significant differences in the use of VLSs across academic majors (Mingsakoon, 2002; Bernardo \& Gonzales, 2009; Hadavi \& Hashemi, 2014). A plausible explanation regarding this result might be attributed to the holistic learning styles of the health science major students. Of all the five categories of the VLS used significantly differently by the health science students, autonomy came first with the highest mean of 3.80. In detail, it was found that two aspects of autonomy strategies were reported as being 'always' used by them: VLS25 (I read English books, newspapers, and magazines outside of class for my own pleasure), and VLS28 (I try to make opportunities outside of class to use words I've just learned). On top of these, they also reported 'often' using another two aspects of autonomy strategies: VLS26 (I listen to English music outside of class time), and VLS29 (I learn new words from all kinds of materials).

As posited by Yu-jing (2010), learning strategies highly depend on individual needs and preferences, health science students in this study could thus be interpreted as more active and determined than the students of other majors in terms of learning English vocabularies. Still, the results also indicated that business, engineering, and agriculture major students were still unaware of the advantages of most of the these strategies, or it might be that they simply did not make efforts to use them. However the findings in this study were contrary to Yilmaz (2017) who reported nonsignificant difference in the use of VLSs between science-oriented and humanities students. This could be explained that the subjects in Yilmaz's research were post-graduate students who might basically possessed good English competence as a result of their being chosen to study at the post-graduate level, hence their similarly reported use of 
VLSs. But the subjects in this study, in all fairness, were undergraduate students and none of whom were English majors. Their English abilities were generally deemed fair, judging from the author's own direct experience of teaching the students at this university. That the health science students in this study were found to be users of more VLSs than other science-oriented students was therefore worth noticing and further investigating.

To draw on the findings from this study, teaching EFL students of all academic majors to enhance their vocabulary repositories requires teaching of different effective strategies on the language teachers' part because as an adage goes "one man's meat is another man's poison", that is; one strategy could not work effectively when used by one learner rather the other. Therefore, language teachers are supposed to consider academic profiles when teaching English vocabulary items to students of various academic majors. Also, the results of this study indicated that the students still did not know nor realize the benefits of other VLSs than the ones they familiarly used, it would therefore be beneficial if they could be taught to be aware of and employ those less frequently used strategies more often in order to enhance their vocabulary learning, which is in fact, the overall improvement of their English abilities (Boonkongsaen, 2012).

\section{IMPLICATIONS AND SUGGESTIONS}

The implications and suggestions which can be drawn from this study are that the language teachers should encourage the students' awareness of the importance and usefulness of VLS in boosting their learning. With more emphasis on strategy training, the teachers can urge the learners to use VLS more effectively.

In regard to the training of VLS, more should be done with the least frequently used strategies (selective attention and memory strategies) because, in principle, the students can employ the strategies to learn more vocabulary by way of both in class and outside of class activities. Particularly, the students from across different majors need different VLSs that suit their learning styles when dealing with academic materials as they need extensive and direct instruction of vocabulary to succeed in their academic studies (Kafipour, et al, 2011).

Most the students in this study reported using online monolingual dictionaries, but not monolingual ones, this lack of interest in capitalizing on a monolingual dictionary implies their inadequate knowledge about how to it. The teachers should help upskill their use of monolingual dictionaries (English-English dictionaries) in an appropriate way. They should tailor the students' attention to the presence of relevant vital information apart from the definition of each entry word, and these pieces of information include, for example, details of lexis and grammar, as well as register. In addition, teachers should place more emphasis on remembering and taking notes of English words by using the learners' second language rather than first language. Dokchandra (2015) proposed that to acquire vocabulary, learners need to put into use the four-element cycle of vocabulary acquisition-noticing, recording, revisiting, and recreating. This suggestion perfectly applies to the Thai university EFL students in the context of this study who are still moderate users of VLS.

Finally, to obtain a more holistic view about the VLS of Thai university EFL students, further research should be carried out at other universities across academic majors and also across the country. Also, in this study health science students were found to have used VLS more frequently than business-oriented and engineering-oriented students, future research should, therefore, investigate the determinants leading to the difference in VLS use between these three academic profiles. Last but not least, it was found in this study that more than half $(58.7 \%)$ of the business-oriented students did not perceive the importance of English while the rest of other majors, especially health science majors, showed a higher level of perception, hence their significantly different use of VLS. Future research should therefore look into the link between perception of students of different academic profiles and their employment of VLS.

\section{REFERENCES}

[1] Al-Khasawneh, F. M. (2012). Vocabulary learning strategies: A case of Jordan University of Science and Technology. English for Specific Purposes World, 12(34), 1-15.

[2] Boonkongsaen, N. (2012). Factors affecting vocabulary learning strategies: A synthesized study. Naresuan University Journal, 20(2), 45-53.

[3] Brahler, C., J., \& Walker, D. (2008). Learning scientific and medical terminology with a mnemonic strategy using an illogical association technique. Advances in Physiology and Education, 12, 219-224. doi:10.1152/advan.00083.2007.

[4] Chinpakdee, M., Nomnian, S., \& Suraratdecha, S. (2014). English vocabulary knowledge and vocabulary learning strategies of Thai undergraduate students in Science program. Proceedings of the 3rd STOU Graduate Research Conference (pp.1-10). Sukhothai Thammatirat Open University, Bangkok, Thailand.

[5] Coady, J, \& Huckin, T (1997). Second language vocabulary acquisition: A rationale for pedagogy. New York: Cambridge University Press.

[6] Dokchandra, D. (2016). The lexical approach: An emphasis on the cycle of vocabulary acquisition. Proceedings of the 9th Annual Conference on Social Sciences, Humanities, and Education, Faculty of Social Sciences and Humanities, Mahidol University. Bangkok, Thailand. Retrieved September 18, 2018, from https://www.researchgate.net/publication/280924556_The_Lexical_Approach_An_Emphasis_on_the_Cycle_of_Vocabulary_A cquisition.

[7] Fan, M.Y. (2000). The dictionary look-up behaviour of Hong Kong students: A large-scale survey. Education Journal, 28(1), 123-138.

[8] Gu, P.Y. (2002). Gender, academic major, and vocabulary learning strategies of Chinese EFL learners. RELC Journal, 33(1), $35-54$. 
[9] Hadavi, M. \& Hashemi, Z. (2014). Comparative Analysis of Vocabulary Learning Strategies in Learning English as a Foreign Language among Freshmen and Senior Medical Sciences Students Across Different Fields of Study. Malaysian Journal of ELT Research, 10(2), 19-33.

[10] Han, Y. (2014). Foreign language vocabulary learning strategies: Patterns of use among college students (Doctoral thesis), Auburn University, Alabama. Retrieved September 15, 2018, from https://etd.auburn.edu/bitstream/handle/10415/4304/Final\%20Submission\%20Yi\%20Han.pdf?sequence=2.

[11] Hashemin, Z. \& Hadavi, M. (2015). Investigation of vocabulary learning strategies among EFL Iranian medical sciences students. Procedia-Social and Behavioral Sciences, 192, 629-637.

[12] Heidar, D.M. \& Hemayati, M.S. (2017). A comparative study of vocabulary learning strategies used by marine engineering students and Iranian EFL learners. RELP, 5(1), 61-72.

[13] Jones, R. (2006). Vocabulary learning strategy use among tertiary students in the United Arab Emirates. Perspective, 14(1), 4-8

[14] Kafipour, R., Yazdi, M. \& Shokrpour, S. (2015). Learning styles and levels of vocabulary learning among Iranian EFL learners. European Journal of Social Sciences, 25(3), 305-315.

[15] Komol, T. \& Sripetpun, W. (2011). Vocabulary learning strategies employed by undergraduate students and its relationship to their vocabulary knowledge. Proceedings of the 3rd International Conference on Humanities and Social Sciences (pp.1-18). Faculty of Liberal Arts, Prince of Songkla University, Thailand.

[16] Mezek, S. (2013). Learning terminology from reading texts in English: The effects of note-taking strategies. Nordic Journal of English Studies, 13(1), 133-161.

[17] Mokhtar, A.A., Raian, R.M., Yahaya, M.F., Abdulla, A. \& Mohamed, A.R. (2018). Vocabulary learning strategies of adult ESL learners. The English Teacher, 38, 133-145.

[18] Nation, I. S. (2001). Learning Vocabulary in Another Language. Cambridge: Cambridge University Press.

[19] Nematollahi, B. Behjat, F. \& Kargar, A.A. (2017). A meta-analysis of vocabulary learning strategies of EFL learners. English Language Teaching, 10(5), 1-10. doi: 10.5539/elt.v10n5p1.

[20] Nirattisai, S. (2014). Vocabulary learning strategies of Thai university students and its relationship to vocabulary size. International Journal of English Language Education, 2(1), 273-285.

[21] Oxford, R. L. (2003). Language learning styles and strategies: An overview. Learning Styles and Strategies/ Oxford, GALA, 125.

[22] Panduangkaew, R. (2018). An analysis of vocabulary learning strategies employed by Thai EFL undergraduates: Dictionary use. rFFLections, 25(1), 116-125.

[23] Puagsang, N. \& Intharaksa, U. (2017). Vocational students' use of vocabulary learning strategies. Pasaa Paritat Journal, 32 , 146-165.

[24] Rabadi, R. I. (2016). Vocabulary learning strategies employed by undergraduate EFL Jordanian students. English Language and Literature Studies, 6(1), 47-58.

[25] Rojananak, K. \& Vitayapirak, J. (2015). Comparison of English vocabulary learning strategies for good and weak learners at King Mongkut's Institute of Technology Ladkrabang. International Journal of Languages, Literature and Linguistics, 1(1), 1-5.

[26] Scharle, A. \& Szabo, A. (2000). Learner autonomy: A guide to developing learner responsibility. Cambridge: Cambridge University Press.

[27] Schmitt, N. (1997). Vocabulary learning strategies. In Norbert Schmitt \& Michael McCarthy (Eds.), Vocabulary: Description, acquisition, and pedagogy. Cambridge: Cambridge University Press.

[28] Schmitt, N. (2000). Vocabulary in language teaching. Cambridge: Cambridge university press

[29] Seddigh, F. \& Shokrpur, N. (2012). Vocabulary Learning Strategies of Medical Students at Shiraz University of Medical Sciences. English Language Teaching, 5(2), 160-173.

[30] Siriwan, M. (2007). English vocabulary learning strategies employed by Rajabhat University students (Doctoral Thesis). Suranaree University of Technology, Nakhon Ratchasima, Thailand.

[31] Suwanarak, K. (2015). Learning English as Thai adult learners: An insight into experience in using learning strategies. English Language Teaching, 8(1), 144-157. doi:10.5539/elt.v8n12p144.

[32] Thammajindarach, C. \& Boonmoh, A. (2017). Student's online dictionary look-up practices. Proceedings of the 6th Burapha University International Conference 2017: "Creativity, Innovation, and Smart Culture for the Better Society". Burapha University, Chonburi, Thailand.

[33] Wilkins, D. A. (1972). Linguistics in Language Teaching. London: Arnold

[34] Yilmaz, V.G. (2017). The role of gender and discipline in vocabulary learning strategy use of Turkish Graduate EFL learners. International Journal of Innovation and Research in Educational Sciences, 4(1), 2349-5219. Retrieved September 18, 2018 from https://www.ijires.org/administrator/components/com_jresearch/files/publications/IJIRES_811_FINAL.pdf.

[35] Yu-jing, H. (2010). Improving English vocabulary teaching in a Chinese university environment. Indonesian Journal of English Language Teaching, 6(1), 1-12.

[36] Zare, P. (2012). Language learning strategies among EFL/ESL learners: A review of literature. International Journal of Humanities and Social Science, 2(5), 162-169. Retrieved October 15, 2018, from http://www.ijhssnet.com/journals/Vol_2_No_5_March_2012/20.pdf.

Sichabhat Boonnoon is a full-time lecturer in English at the Faculty of Liberal Arts and Management Science, Kasetsart University, Sakon Nakhon province, Thailand. She holds a master's degree in Teaching English as a Second Language from Silpakorn University, Thailand. Her research interests cover the areas of second language (L2) reading and writing, vocabulary learning strategy and teaching, academic English teaching approaches, and Teaching English to speakers of other languages (TESOL). 